\title{
Albert Hirschman na América Latina e sua trilogia sobre desenvolvimento econômico ${ }^{1}$
}

\author{
Ana Maria Bianchi ${ }^{2}$
}

\section{Resumo}

Este artigo discute a trilogia de Albert Hirschman sobre desenvolvimento econômico, que se inspirou em sua prolongada estada na América Latina e em suas viagens para diversos países em desenvolvimento durante as décadas de 1960 e 1970. Após uma revisão de cada um dos livros que compõem a trilogia há uma seção metodológica, onde discuto a tendência do autor de ultrapassar barreiras disciplinares, sua profunda preocupação com a prática e com a relevância política, e a orientação empírica de seu método de investigação. A seção final propõe caminhos para futuras investigações.

Palavras-chave: Hirschman, Albert O., 1915-; Desenvolvimento econômico - América Latina.

\section{Abstract \\ Albert Hirschman in Latin America and his trilogy on economic development}

This paper discusses Albert Hirschman's trilogy on economic development, which was inspired by his extended stay in Latin America and by his travels to several developing countries during the 1950s and the 1960s. After a review of each book making the trilogy there is a methodological section, where I discuss Hirschman's tendency to trespass disciplinary boundaries, his deep concern with practice and political relevance, and his empirically oriented method of research. The closing section raises some possibilities for further research.

Key words: Hirschman, Albert O., 1915-; Latin America - Economic development. JEL A31, O10.

A economia do desenvolvimento emergiu como novo campo de pesquisa no final da Segunda Grande Guerra. Bostaph e outros (1998) associam esse evento à migração e ao reassentamento nos Estados Unidos da América de economistas de origem judaica, que fugiram da Europa de Hitler e ajudaram a fundar o novo programa de pesquisa. A motivação deste artigo, porém, não é falar sobre o destino final desses pioneiros no campo do desenvolvimento econômico, mas, antes, apontar a influência que a residência na América Latina e as viagens para diversos países subdesenvolvidos durante as décadas de 1960 e 1970 tiveram

(1) Trabalho recebido em agosto de 2006 e aprovado em março de 2007. Versões anteriores deste artigo foram apresentadas na $9^{\text {a }}$ Conferência Européia sobre a História de Economia (ECHE) e no XXXII Encontro Nacional de Economia da Anpec. Sou grata a José Luís Cardoso e Dante Mendes Aldrighi por seus comentários e sugestões. Também agradeço aos bibliotecários da Seeley G. Mudd Manuscript Library, na Universidade de Princeton.

(2) Professora da Faculdade de Economia, Administração e Contabilidade da Universidade de São Paulo (USP) e bolsista do CNPq (Conselho Nacional de Desenvolvimento Científico e Tecnológico). 
sobre um deles, Albert Hirschman, nascido em Berlim em 1915. Essa significativa experiência profissional e de vida inspiraram Hirschman a escrever diversos livros e artigos, e estes, a seu turno, tiveram um efeito de recrutamento, ajudando a tornar o novo campo de desenvolvimento econômico atraente e excitante para muitos jovens pesquisadores. O foco aqui está nos escritos de Hirschman que resultaram de sua experiência profissional na Colômbia, Brasil, Chile e outros países latino-americanos, e de suas freqüentes viagens a outros países subdesenvolvidos entre 1952 e 1965. Mais especificamente, discutirei os três livros que constituem sua trilogia em desenvolvimento econômico, a saber: The strategy of economic development (1958), Journeys toward progress (1963/1968), e Development projects observed (1967). ${ }^{3}$

Um aspecto interessante de se escrever sobre Hirschman é o fato de que ele volta sempre para os mesmos assuntos, ao relançar suas proposições, explorar diferentes ângulos e reintroduzir seus argumentos de forma modificada. Em certo sentido, é como se ele tivesse escrito um único livro durante sua vida, como tentarei apontar neste artigo. Mesmo depois de ter mudado para outros temas de pesquisa, ele continuou empregando conceitos construídos em seus escritos anteriores, em obras como Exit, voice and loyalty (1970), A bias for hope (1971), The passions and the interests (1977), Essays in trespassing (1981), A dissenter's confession: 'the strategy of economic development' revisited (1984), Rival views of market society and other recent essays (1986), The rhetoric of reaction (1991), A propensity to self-subversion (1995) e Crossing boundaries (1998). Na verdade, o trabalho de Hirschman sobre desenvolvimento econômico não representou apenas uma contribuição pioneira e inovadora para este programa de pesquisa; ele também influenciou todos os seus escritos subseqüentes, onde o autor cruzou a ponte para outros amplos temas das ciências sociais.

Meu foco inicial recai no conteúdo básico de cada um dos livros que compõem a trilogia, aos quais são devotadas as seções 1 a 3 deste artigo. Na seção 4 discuto três traços metodológicos do trabalho de Hirschman sobre desenvolvimento econômico, que respondem pela originalidade de sua abordagem. Ao final sumarizo as principais conclusões obtidas no caminho, mas, principalmente, levanto possibilidades de extensões e pistas para novas pesquisas.

\section{The strategy}

Quando Hirschman chegou pela primeira vez na América Latina, em 1952, a Colômbia era um país muito pobre, com uma população de 12,6 milhões

(3) No mesmo campo Hirschman também escreveu A bias for hope, publicado em 1971. Entretanto, Bias não é um livro original, pois consiste em uma coleção de artigos que haviam sido anteriormente publicados em outros veículos. 
de pessoas. A expectativa de vida ao nascer era de 50,6 anos e a taxa anual de incremento populacional era superior a 3\%, uma das mais altas taxas de todo o mundo. A economia colombiana era primordialmente agrícola, sendo que $60 \%$ da população habitava na zona rural e o setor agrícola era responsável por $40 \%$ do produto doméstico bruto.

Sarmiento (1992) destaca que a estrutura econômica então prevalecente "estava bem ajustada para perpetuar o subdesenvolvimento". Enquanto as exportações baseavam-se em produtos primários altamente inelásticos, a produção de bens de consumo agrícolas e industriais dependia da importação de bens de capital e intermediários. O país dispunha de poucas divisas e havia oportunidades limitadas de expansão das exportações primárias, obstáculo que fora bem caracterizado por Raúl Prebisch na introdução de um documento da Cepal, a Comissão Econômica da ONU para a América Latina. Em 1950, a Colômbia tomou seus primeiros passos para o desenvolvimento industrial: o governo estabeleceu um sistema de tarifas e refinou e codificou medidas políticas destinadas a proteger a indústria nascente (Sarmiento, 1992, p. 142).

Em uma longa entrevista com três pesquisadores italianos (Crossing boundaries, 1998), Hirschman observa que o fato de seus interesses terem se deslocado para os problemas do desenvolvimento nos chamados países atrasados fora responsável por sua decisão de mudar-se para a Colômbia. Ele havia passado os sete anos imediatamente anteriores trabalhando como economista para o Federal Reserve Board, o banco central dos Estados Unidos. Suas atividades envolviam projetos referentes à reconstrução econômica européia, sob o Plano Marshall. "Um pouco cansado" de revolver sempre em torno dos mesmos problemas, como ele explica, Hirschman decidiu mudar-se para a Colômbia, na qualidade de consultor do recém-estabelecido Conselho Nacional de Planejamento, por indicação do Banco Mundial. ${ }^{4}$

Hirschman chegou a Bogotá em 1952, como consultor prático contratado pelo governo colombiano. Ele estava com quase 37 anos e já tinha publicado vários artigos, mas apenas um dos muitos livros que publicaria mais tarde. Um ano após sua chegada, o país experimentou um golpe de estado liderado por Rojas Pinilla, o chefe das forças armadas, que desencadeou um período de inquietação civil, lei marcial e violência. Do ponto de vista de seu desenvolvimento industrial, contudo, houve progresso na década de $1950 .{ }^{5}$

(4) Na verdade, Hirschman revelou na entrevista que tinha duas possibilidades: mudar-se para a Colômbia (sua opção favorita) ou ir para a Europa com a European Payments Union, organização criada pela Organização para a Cooperação Econômica Européia. Ele tomou a primeira via por ter sido atraído pelo desafio que colocava para ele (Hirschman, 1998, p. 80).

(5) Em uma entrevista pessoal que me concedeu em outubro de 2004, Hirschman definiu a Colômbia daquele tempo como um país "pobre, mas com possibilidades". Para maiores detalhes sobre a ditadura de Rojas Pinilla e seu Ministro da Fazenda, Carlos Villaveces, ver Hirschman (1963, p. 123-125). 
A estada de Hirschman na Colômbia durou quase cinco anos. Nos dois primeiros trabalhou em íntima conexão com o governo nacional; no período restante atuou como consultor econômico e financeiro privado. Em 1956 ele voltou aos Estados Unidos, onde se estabeleceu como professor visitante da Universidade de Yale. Contudo, fez muitas outras viagens às Américas do Sul e Central, em visita a projetos financiados pelo Banco Mundial. O mesmo interesse em economia do desenvolvimento levou-o a países em desenvolvimento da Ásia, África e Europa.

Este foi o cenário mais amplo que inspirou Hirschman a escrever The strategy, publicado pela primeira vez em $1958 .{ }^{6}$ Meldolesi $(1995$, p. 49) descreve o período colombiano de Hirschman como uma "colheita prodigiosa", que requereu dele um novo compromisso intelectual e representou um solo extremamente fértil para a germinação das idéias que trouxera consigo.

The strategy aborda alguns processos básicos que configuram o progresso econômico nos países em desenvolvimento. Ele advoga o estabelecimento de indústrias com fortes encadeamentos para trás (backward linkages) como estratégia para promover o desenvolvimento. O padrão de crescimento desequilibrado resultante da adoção generalizada dessa estratégia - que o autor retrataria mais tarde como uma "invenção social notável, por meio da qual políticas pluralistas e o alcance de objetivos sociais múltiplos pode ser reconciliada" (Hirschman, 1984, p. 109) - gerou muita controvérsia no campo de desenvolvimento econômico. Ainda assim, uma versão formalizada da noção de encadeamentos foi assimilada pela teoria econômica mainstream, na forma de índices de desenvolvimento que identificam setores-chave na economia. Ela tornou-se sabedoria convencional entre economistas contemporâneos que fazem pesquisa em teoria do desenvolvimento e economia regional. ${ }^{7}$

O principal capítulo em The strategy é o capítulo 4, onde Hirschman expõe a idéia de uma estratégia de desenvolvimento desequilibrada (Unbalanced growth: an espousal), aí definindo seu comprometimento maior com a idéia do desenvolvimento como uma "cadeia de desequilíbrios":

...our aim must be to keep alive rather than eliminate the disequilibria of which profits and losses are symptoms in a competitive economy. If the economy is to be kept moving ahead, the task of development policy is to maintain tensions, disproportions, and disequilibria. That nightmare of equilibrium economics, the endlessly spinning cobweb, is the kind of mechanism we must assiduously look for as an invaluable help in the development process (Hirschman, 1958, p. 66).

(6) Além da edição inglesa, referida no final deste artigo, existe uma tradução brasileira do livro de Hirschman publicada pela Fundo de Cultura em 1961.

(7) Ver Sonis et al. (1995) para uma aplicação. 
Esta ousada proposição enfatiza a natureza desordenada do desenvolvimento econômico. Ela questiona as generalizações e perspectivas teóricas que haviam até então prevalecido entre economistas envolvidos com problemas de desenvolvimento. ${ }^{8}$ No capítulo anterior, Hirschman atacara a tese do crescimento equilibrado que havia sido defendida por seus antecessores no campo. Ele argumentara que os problemas de industrialização não requeriam uma solução simultânea, como alegavam economistas como Paul N. Rosenstein-Rodan, Ragnar Nurkse, Arthur Lewis e Tibor Scitovsky. Pelo contrário: os novos processos de industrialização favoreceriam uma série de soluções seqüenciais que eram essencialmente diferentes daquelas seguidas pelos países industriais mais velhos. Em vez de enfatizar os vários obstáculos ao progresso econômico - sistemas de propriedade fundiária, estrutura familiar, instabilidade administrativa, falta de poupança e assim por diante -, Hirschman escolheu destacar a necessidade de mecanismos de indução. Em sua visão, o problema fundamental do desenvolvimento consistia em gerar e canalizar energias humanas na direção desejada (Hirschman, 1958, p. 25). Desnecessário dizer, esta atitude era consistente com seu papel como consultor prático.

Na concepção de Hirschman, encadeamentos para trás correspondiam a enviar estímulos para setores que forneciam os insumos requeridos por uma atividade qualquer, enquanto encadeamentos para frente induziam o estabelecimento de novas atividades que utilizavam o produto da atividade proposta. A principal fonte de desenvolvimento seria dada por atividades com alto potencial de gerar encadeamentos, principalmente encadeamentos para trás.

A idéia de que o desenvolvimento industrial deveria (e, de fato, iria) proceder amplamente por meio de encadeamentos para trás era revolucionária, na época, pois implicava que um país que quisesse industrializar-se não deveria fazer as coisas da forma convencional. Ao contrário, o desenvolvimento industrial encontraria seu caminho dos "últimos toques" à indústria intermediária e básica. A industrialização de setores líderes arrastaria atrás de si o resto da economia. Nesse sentido, não seria viável ou desejável suprimir as tensões e os desequilíbrios criados pelo processo de desenvolvimento, uma vez que haveria uma "virtude criativa" nos mesmos.

Se o desequilíbrio é um mecanismo intencional, como o equilíbrio deve ser restaurado? Hirschman o apresenta como resultado de pressões, incentivos e compulsões. Ele sugere que o caminho eficiente em direção ao desenvolvimento econômico freqüentemente emerge em circunstâncias nas quais o país deve encontrar solução para gargalos e carências de habilidades, facilidades, serviços e produtos.

(8) Como o autor admitiria mais tarde: "To write in praise of lack of balance is evidently a provocation for which a price must be paid" (Hirschman, 1984, p. 104).

Economia e Sociedade, Campinas, v. 16, n. 2 (30), p. 131-150, ago. 2007. 
Embora Hirschman fale sobre os efeitos pecuniários e tecnológicos dos encadeamentos, ele dá maior atenção aos primeiros. Importantes encadeamentos para trás operariam por meio de aumentos nos lucros para as indústrias fornecedoras, à medida que a demanda de seus produtos aumentasse. Quanto aos encadeamentos para frente, eles decorreriam de reduções de custo que levariam a um aumento dos lucros alcançáveis por seus usuários potenciais.

Enquanto no capítulo 4 de The strategy Hirschman apóia-se em considerações teóricas para defender sua tese principal, no capítulo 8 ele leva em conta evidência empírica sobre o processo de industrialização em curso na Colômbia. Sugere que os países menos desenvolvidos podem ter uma vantagem comparativa em tarefas como a operação de linhas aéreas, em contraposição a tarefas como construção e manutenção de estradas. Isso ocorreria porque nas últimas a compulsão para manter não é forte - a falta de manutenção não tem consequiências drásticas imediatas. Em contraste, a falta de manutenção no setor aéreo implica penalidades severas, que incluem perdas maciças de vida e propriedade. A conclusão segue-se logicamente: ao contrário do senso comum (e àquilo que outros economistas antes dele argumentavam), os países subdesenvolvidos poderiam alcançar um sucesso considerável em empreendimentos com uma tecnologia complexa, nas quais o hábito de manutenção poderia ser adquirido e difundido para o resto da economia (Hirschman, 1958, p. 142).

Hirschman parte então para a seguinte generalização: em certas circunstâncias, poderia ser racional para os governos de países subdesenvolvidos concentrar-se em "show-pieces". Ao assumir a construção de uma grande estação hidroelétrica ou de uma usina siderúrgica, um determinado governo não desejaria correr o risco de deixar que esses empreendimentos dessem errado. Ele estaria fortemente compelido a assegurar o sucesso do empreendimento, em contraste com a aplicação dos mesmos recursos em um grande número de pequenos projetos (Hirschman, 1958, p. 144). Graças a seus fortes encadeamentos para trás, certas indústrias altamente capital-intensivas era particularmente adequadas para países subdesenvolvidos. Sequiências desse tipo, que envolviam "colocar o carro diante dos bois", caracterizariam o processo de desenvolvimento econômico e social dos latecomers.

Syrquin (1992) assinala que, embora idéias semelhantes possam ser encontradas em autores como W.W. Rostow, Alexander Gerschenkron e François Perroux, Hirschman foi o primeiro economista a desenvolver a idéia de encadeamentos como a espinha dorsal de uma estratégia deliberada de desenvolvimento. Encadeamentos implicam interdependência. O termo pode ser usado para apontar inter-relações em um sistema de equilíbrio geral, onde tudo depende de tudo, mas também para denotar uma variedade de efeitos 
multiplicadores, inclusive de transbordamento (spill-over). Em The strategy, o conceito adquiriu um significado mais específico e concreto, sendo usado para designar mecanismos de indução em ação no setor de atividades diretamente produtivas.

Um aspecto importante da originalidade da abordagem de Hirschman é o fato de ter sido capaz de realizar a dimensão psicológica da estratégia desenvolvimentista. Ele não foi o primeiro economista a recomendar projetos com potencial de efeito-demonstração (showcases) como estações hidroelétricas e linhas aéreas, sob o argumento de que estimulariam o desenvolvimento ao criar encadeamentos com outros setores da economia. Contudo, ele fez mais: apontou para uma verdadeira vantagem desses projetos de grande porte, que era o fato de que tendem a permitir um certo nível de escrutínio público, assim minimizando o risco de corrupção e de baixos padrões de desempenho. ${ }^{9}$

Ao retomar essa tese em A propensity to self-subversion, Hirschman (1995) argumenta que o núcleo de seu argumento era contrapor-se à idéia de "uma coisa de cada vez". Os países de industrialização tardia deveriam seguir um caminho original, definido como uma seqüência de crescimento desequilibrado. $\mathrm{O}$ desenvolvimento industrial de países menos desenvolvidos procederia assim, tipicamente, por meio de encadeamentos para trás, que era o caminho certo a seguir, uma vez que a solução seqüencial de problemas envolveria o risco de estagnação.

Idéia semelhante é encontrada na tese do risco, que Hirschman desenvolveu em estágio posterior, em The rhetoric of reaction (1991) e novamente em Propensity. Defensores dessa tese sustentam que um passo à frente pode colocar em risco um passo anterior que deve se avaliado de forma mais positiva do que aquele que o segue. Para Hirschman, a tese do risco poderia aplicar-se a países como a Inglaterra, com toda uma história de mudança social e política gradual, mas não a países com uma experiência histórica diferente. Com a oferta de bens intermediários e de capital vindo do exterior, os países de industrialização tardia estavam capacitados a mover-se livremente, de acordo com a dinâmica dos encadeamentos para trás, dos últimos estágios de produção para os primeiros e daí para a produção de bens de capital (Hirschman, 1995, p. 73).

Na conclusão de The strategy, Hirschman encara seu próprio argumento "em perspectiva" (p. 208) e faz algumas advertências sobre as teses ousadas que propusera nos capítulos anteriores. Ele admite algum desconforto sobre a importância e a virtude criativa atribuídas a pressões, tensões e desequilíbrios. Da

(9) Como se argumenta na seção 4 abaixo, há uma estreita conexão entre o conceito de latitude, associado a projetos de grande porte, e o conceito de voz, que designa ação política, sobre o qual o autor falaria em seu livro de 1970, Exit, voice and loyalty.

Economia e Sociedade, Campinas, v. 16, n. 2 (30), p. 131-150, ago. 2007. 
mesma forma, concede que a resposta a tais situações pode ser às vezes destrutiva, um perigo que não conviria desconsiderar (p. 208). ${ }^{10}$ Isso não implicava, porém, que tais tensões fossem indesejáveis e que não devessem ocorrer. De fato, os países subdesenvolvidos já estavam operando sob a forte tensão decorrente do desejo universal por melhoria econômica estranhamente combinado com muitas resistências à mudança (p. 209). Como seria possível extrair o máximo dessa relação positiva entre o desenvolvimento e as tensões por ele criadas? Pela difusão da assistência técnica e do aconselhamento político aos países subdesenvolvidos. ${ }^{11}$

Hirschman atribui o sucesso desse conceito de encadeamentos ao fato de ser mais operacional e menos ambíguo do que os conceitos alternativos. (Essays in trespassing, 1981, p. 63). À medida que as matrizes de insumo-produto rapidamente se acumulam, uma série substancial de estimativas empíricas de encadeamentos para frente e para a trás começaram a ser publicadas, juntamente com a literatura metodológica sobre a mensuração de encadeamentos. (Hirschman voltaria a esse conceito no capítulo 4 de Essays, acrescentando vários outros efeitos de encadeamento e generalizando ainda mais o conceito.)

\section{Journeys}

O segundo livro na trilogia de Hirschman, Journeys toward progress, publicado em 1963, trata dos processos políticos envolvidos nas mudanças econômicas retratadas em The strategy. Ele foi elaborado durante o verão de 1960, quando o autor fez uma viagem prolongada a México, Colômbia, Chile, Argentina e Brasil. Ele queria conhecer como as autoridades públicas na América Latina agiam para solucionar seus severos problemas sociais. Isso resultou em uma tentativa de captar a maneira latino-americana de lidar com problemas de política, com suas virtudes e suas limitações.

Como Eli Heckscher assinala na introdução do livro, Hirschman estava consciente das dificuldades de se generalizar sobre processos de elaboração de políticas na América Latina, e propôs ao Twentieth Century Fund ${ }^{12}$ um estudo "that would attempt to reach conclusions through painstaking observation of the sequence of policy-making around significant policy problems". Journeys é o fruto

(10) Em "The political economy of import-substituting industrialization in Latin America", escrito dez anos após The strategy e publicado em Bias, Hirschman reconhece a possibilidade do desenvolvimento industrial estagnar-se a ponto de impossibilitar totalmente sua continuidade.

(11) Em artigo publicado em 1962 com Charles E. Lindblom (republicado em Bias), Hirschman apresenta uma versão formalizada do conceito de encadeamentos. Os autores montam uma representação geométrica simplificada do crescimento equilibrado vs. desequilibrado, com base em uma economia de dois setores.

(12) O Twentieth Century Fund é uma fundação para pesquisa científica e educação pública em assuntos econômicos da atualidade, fundada em 1919. 
deste esforço, definido pelo autor como uma expedição aventureira à vasta terra de ninguém que se estende entre a economia e as outras ciências sociais, como a política, a sociologia e a história (p. ix).

O livro começa com a análise de três casos concretos: Brasil, Colômbia e Chile. ${ }^{13}$ Estas três histórias, contadas na primeira parte, são vistas por Hirschman como constituindo a essência do livro. Ao criticar sociólogos como David McClelland e Everett E. Hagen, que enfatizaram o papel da tomada de decisão empresarial na decolagem para o desenvolvimento, o autor argumenta que a tomada de decisão desempenha um papel considerável em todas as etapas do desenvolvimento (p. 3). Ele também questiona a doutrina laissez-faire na economia, que assume que a tomada de decisão por parte do setor publico é, em média, de qualidade inferior àquela tomada pela iniciativa privada (p. 5). Seu próprio interesse no tema incluía não apenas a qualidade de tomada de decisão pública em determinado contexto institucional, como também a habilidade de se realizar mudanças importantes nesse próprio contexto (p. 6).

Hirschman começa sua análise descrevendo os vários passos e discussões políticas que levaram à criação da Sudene (Superintendência para o Desenvolvimento do Nordeste) pelo presidente Juscelino Kubitschek, em 1959. Ele retrata o nordeste brasileiro como uma região problemática durante os (até então) últimos 80 anos, sujeita a severas secas periódicas, que afetavam uma vasta população, com um sistema fundiário muito desigual. Descreve então o processo de criação de uma instituição bancária regional e menciona o papel importante desempenhado pelo economista Celso Furtado, apontada como superintendente do órgão. ${ }^{14}$

O capítulo 2 é dedicado ao uso e à reforma da terra na Colômbia. Após uma extensa reconstituição histórica, onde questiona a idéia dominante de persistência de "padrões feudais" na América Latina, Hirschman passa a analisar as várias leis promulgadas pelas autoridades colombianas para reformar o sistema de posse da terra. Elas incluíam a Lei 200 de 1936, a que se seguiu, em 1949, a implementação de medidas fiscais para induzir os proprietários a cultivar suas terras, e a reforma agrária promovida pela adoção da Lei 135, em 1961, assinada pelo presidente Alberto Lleras. Uma seção interessante do mesmo capítulo focaliza as vantagens e limitações das recomendações de uma missão estrangeira, assunto ao qual retornaria muitas vezes em Journeys.

(13) Nos arquivos da Biblioteca Mudd (caixas 6 e 7) há também material sobre Argentina e México. Pressionado por sua agenda, porém, Hirschman decidiu deixar estes países fora de Journeys.

(14) Sua longa entrevista com Furtado, que havia previamente trabalhado na Cepal, faz parte dos manuscritos enviados aos arquivos da Biblioteca Mudd.

Economia e Sociedade, Campinas, v. 16, n. 2 (30), p. 131-150, ago. 2007. 
O terceiro capítulo trata do problema da inflação no Chile. Mais uma vez, o tema é introduzido por uma reconstituição histórica detalhada, que principia na década de 1830. O autor descreve como Courcelle-Seneuil, o primeiro professor de economia da Universidade do Chile, ajudou o governo a produzir uma lei que estabelecia o princípio do livre funcionamento dos bancos. O retorno ao padrãoouro em 1925 é definido como um episódio significativo na história recente do Chile, sob a influência da Missão Kemmerer, assim intitulada por conta do professor norte-americano que veio para o país como consultor do governo. De acordo com Hirschman, embora as regulamentações adotadas em 1925 tenham evitado alguns dos erros cometidos em anos anteriores, elas mais uma vez traziam os riscos associados a uma aplicação estrita das doutrinas importadas. Em suas próprias palavras,

...the experience again left a most bitter taste. It displayed once more that propensity [...] to take imported doctrines more seriously and to apply them more rigidly and dogmatically in a foreign country than in their country of origin (Hirschman, 1963, p. 180).

Vieram em seguida os anos "radicais" de 1939-1952, quando as taxas de inflação cresceram continuadamente a uma taxa média anual de $18 \%$. Hirschman atribui a "prolongada complacência em relação à inflação" no Chile neste período à atmosfera mundial de inflação que prevaleceu durante a Segunda Grande Guerra e nos anos imediatamente seguintes. A inflação era vista pelas autoridades do Banco Central como o preço a ser pago pela rápida expansão econômica. Não obstante, em 1949 o governo chileno solicitou à ONU e em seguida ao Fundo Monetário Internacional uma missão de consultores econômicos. Ambas as instituições enviaram missões que desembarcaram em Santiago praticamente ao mesmo tempo. Embora houvesse economistas de prestígio nos dois times, acrescenta Hirschman, tais missões "estavam desde o início condenadas à futilidade" (Hirschman, 1963, p. 191).

Em 1955-1956, uma nova missão estrangeira veio ajudar as autoridades monetárias a combater a inflação: a Missão Klein-Saks. Hirschman relata que a ordem pública em Santiago estava então constantemente ameaçada por greves e outras demonstrações de protesto, a um ponto tal que o exército começou a acampar nas ruas, na tentativa de assegurar a ordem constitucional. O governo Ibañez decidiu então contratar uma firma de consultores (Klein e Saks) sediada em Washington, que havia previamente trabalhado no Peru.

Ao avaliar a eficácia das recomendações feitas por essa nova missão, Hirschman conclui que sua contribuição técnica foi mínima, uma vez que se apoiou em planos e idéias já existentes. ${ }^{15}$ Entretanto, à semelhança do que ocorrera

(15) Hirschman retomaria esta idéia em "A dissenter's confession" (p. 93), onde se refere à "síndrome do economista visitante". 
no caso Kemmerer, o papel dessa nova missão foi importante para cimentar uma nova coalizão política.

Hirschman passa a discutir os eixos e principais proposições da chamada escola estruturalista da inflação, uma doutrina original elaborada por economistas latino-americanos. Em vez de ver a inflação como o mal fundamental da sociedade chilena, como era o caso de outras correntes de pensamento, os estruturalistas argumentavam que a busca de causas gerais subjacentes ao problema da inflação poderia ajudar a sociedade a combatê-la. Reformas estruturais básicas na economia eram, portanto, necessárias para suprimir a inflação. ${ }^{16}$

Em seguida a uma longa revisão da história econômica do Brasil, da Colômbia e do Chile, Hirschman dedica o capítulo 4 à seguinte questão: existe um estilo latino-americano de resolver problemas e fazer política? Para respondê-la, ele introduz na página 238 uma expressão francesa que se tornaria central em seu pensamento: la rage de vouloir conclure (a raiva de querer concluir). ${ }^{17}$ Ao empregar essa expressão ele pretende caracterizar o estilo de resolução de problemas dos países de industrialização tardia. Sem dúvida, essa caracterização é altamente contextual: problemas sociais urgentes como aqueles expressos pelos camponeses colombianos, os nordestinos famintos no Brasil e os trabalhadores chilenos demandavam respostas rápidas dos tomadores de decisão, que precisavam voltar suas ações, em um primeiro momento, apenas para pacificar os protestos. Isso freqüentemente os levaria a pular para uma solução pronta, uma vez que

Urged on by pressing problems and by the desire to catch up, and liberally supplied with recipes communicated to them by the advanced countries of both East and West, their policy-makers are only too ready to believe that they have achieved full understanding and to act on the basis of this belief (Hirschman, 1963, p. 240).

Neste ponto, Hirschman retoma um assunto sobre o qual já falara bastante em The strategy, que diz respeito aos problemas especiais enfrentados pelos países de industrialização tardia. Tudo o que podem fazer, ele argumentara em The strategy, é seguir uma rota aberta por outros muito tempo antes. Entretanto, ao assumir esse tipo de desenvolvimento derivado, podem enfrentar obstáculos adicionais de natureza psicológica, que envolveriam um "vago ressentimento"

(16) Para um panorama da abordagem estruturalista da inflação, ver Danby (2005). Hirschman valorizava a "reformmongering" e uma atitude de resolução de problemas como saída do subdesenvolvimento. Este foi um dos muitos pontos de desacordo que teve tanto com os autores institucionalistas como com aqueles associados à teoria da dependência, que tendiam a defender soluções revolucionárias. Nos manuscritos da Biblioteca Mudd há muitas referências feitas por Hirschman à literatura psicológica sobre resolução de problemas. Sobre esse assunto, ver também Coser (1984) e Meldolesi (1995).

(17) Como explica em rodapé, a expressão é tomada de empréstimo ao escrito francês Gustave Flaubert, que a empregou para ridicularizar a reação dos pensadores do século XIX ao rápido crescimento de países industriais. Há outras citações de Flaubert na Caixa 5 dos documentos da Biblioteca Mudd, o que sugere que se trata de um autor favorito de Hirschman. Ver Meldolesi (1995) para mais detalhes. 
contra as novas maneiras de fazer, uma "esperança secreta" de que os equipamentos e métodos não irão funcionar no novo ambiente (Hirschman, 1958, p. 139).

Essa atitude ambivalente é novamente descrita em Journeys, onde Hirschman adota um apelido significativo para retratá-la: "complexo de fracasso" (failure complex) (p. 240). Da raiva de querer concluir ele se move para essa segunda expressão, que denota o que pode ser tomado como um "estilo autodepreciativo de fazer política", observado entre os políticos latino-americanos. Em poucas palavras, o complexo de fracasso - fracassomania, como ele o apelida em artigo publicado em 1968 e incluído em Bias for hope - refere-se à tendência de se considerar os problemas como totalmente não resolvidos ou, pelo contrário, totalmente solucionados. Movidos por um desejo compulsivo de resolver todos os problemas o mais rapidamente possível (la rage...), os formuladores de política inclinam-se a buscar uma solução "fundamental", para a qual contam com a consultoria estrangeira. O entusiasmo freqüentemente excessivo com o qual missões especialistas são saudadas em sua chegada à América Latina faria parte desse padrão ambivalente. Não há rejeição, mas, ao contrário, uma atitude de aceitação qualificada por sabotagem (inconsciente). $\mathrm{O}$ fato de Hirschman ter denominado seu livro seguinte sobre desenvolvimento econômico de "A bias for hope", ou seja, um viés para a esperança, claramente revela sua intenção de contrabalançar a fracassomania.

As três histórias relatadas em Journeys têm alguns exemplos desse traço psicológico coletivo, como Hirschman explicaria mais detalhadamente depois. A reforma agrária promovida pelo governo colombiano na década de 1930 induziu mudanças em uma direção desejável, mas foi sempre interpretada como um total fracasso. No nordeste brasileiro, algumas iniciativas públicas para combater os persistentes problemas de seca foram vistos como totalmente ineficientes, embora tivessem sido relativamente bem-sucedidos (Hirschman, 1998, p. 100).

Em vez dessa busca de uma solução total para os problemas do desenvolvimento, Hirschman defende ganhos incrementais e uma estratégia de resolução de problemas. Como Coser (1984, p. 166) observa, o autor vê o desenvolvimento como a criação de meios institucionais para trazer à vida recursos potenciais. Não há rota predeterminada para esta meta; tudo depende de soluções criativas aplicadas a circunstâncias concretas.

\section{Development projects}

O livro Development projects observed, publicado em 1967, concentra-se na análise dos aspectos microeconômicos do desenvolvimento, tais como a construção e a manutenção de rodovias, estações elétricas e esquemas de irrigação. 
Seu material empírico diz respeito a onze projetos do Banco Mundial espalhados pelo mundo, que compreendem projetos de irrigação no sul da Itália, no Peru e na Tailândia, telecomunicações na Etiópia, estradas de ferro na Nigéria, uma indústria de papel e pergaminho no Paquistão etc. No início do livro Hirschman esclarece que fez um esforço de olhar "além da tecnologia", para enfatizar, no lugar dela, o ambiente social e cultural no qual projetos de desenvolvimento estão enraizados.

Um capítulo importante, intitulado "Latitudes and disciplines" (cap. 3), lida com uma grande variedade de pressões para desempenho desencadeadas por várias características do projeto: latitude espacial ou locacional, disciplina temporal na construção, tolerância à corrupção, latitude na substituição de quantidade por qualidade, delineamentos privados por públicos e assim por diante. O conceito de latitude surge de observações empíricas feitas em The strategy, sobre o melhor desempenho dos países de industrialização tardia na manutenção de aviões em comparação com estradas. Hirschman conclui desta evidência empírica que, para um país com pouca tradição industrial, um certo tipo de tecnologia avançada, capital-intensiva, pode ser mais adequada do que a tecnologia trabalho-intensiva.

Hirschman define latitude como a característica do projeto que permite ao planejador e ao operador moldá-lo, ou deixá-lo tomar um rumo específico, independentemente de ocorrências externas (p. 86). Seu principal argumento tem a ver com a maior ou menor latitude em padrões de desempenho prevalecentes em uma dada atividade industrial. Quando essa latitude é estreita (o que implica baixa tolerância para um mau desempenho) a tarefa correspondente deve ser desenvolvida de maneira claramente definida, pois há a possibilidade de não poder ser desenvolvida de todo ou de envolver um nível de risco considerável. Aviões, por exemplo, envolvem alta probabilidade de desastre, com conseqüências dramáticas. O mesmo não se aplica às estradas de rodagem, cujos padrões de desempenho e riscos associados são bem menores. Todas as categorias acima mencionadas provaram-se bastante úteis no entendimento das dificuldades e das conquistas específicas observadas nos diferentes projetos visitados por Hirschman. Ao refinar o conceito de latitude, o autor ganha um melhor entendimento do mesmo: falta de latitude, diz ele, tem a vantagem da determinação, de evitar acidentes fortuitos; ela acelera os processos de decisão e equipa os gestores com disciplina e guias de ação. Enquanto em algumas situações a presença de latitude foi útil para estimular a adaptação de modelos importados de comportamento econômico às condições e às demandas locais (p. 127), em outras, a falta de latitude favoreceu mudanças que têm lugar de forma descontínua, envolvendo novos valores e tipos de comportamento (p. 139). 
Nesse sentido, outro conceito central em Development projects é o chamado princípio da mão escondida (principle of the hiding hand), uma metáfora inspirada no conceito weberiano de conseqüências não intencionais da ação humana. Ele se associa a uma das idéias mais caras a Hirschman, que é a busca de racionalidades ocultas.

Como a mão escondida atua em situações concretas? Projetos de desenvolvimento estão sujeitos a dois tipos de desdobramentos potenciais: ameaças insuspeitadas, de um lado; e ações remediais que podem ser tomadas sempre que as mesmas se tornarem reais, de outro. Planejadores de projeto tais como os fazendeiros que Hirschman visitou no Uruguai tendiam a ignorar ou subestimar a extensão de trabalho (trait-making) que um determinado projeto requeria. ${ }^{18}$ Se tivessem informação completa sobre as dificuldades envolvidas em sua implementação, eles poderiam ter decidido abandonar o projeto. Ao fazê-lo, porém, nunca alcançariam as soluções alternativas que depois se tornariam as grandes virtudes de seu projeto. Uma "mão escondida" colaborativa levou os planejadores a assumir projetos que ex ante poderiam ter-lhes parecido inviáveis.

\section{De um ponto de vista metodológico}

Depois dessa revisão da trilogia escrita por Albert Hirschman por inspiração de suas viagens à América Latina e outros países subdesenvolvidos, dedicarei esta seção a comentar alguns aspectos metodológicos da abordagem do autor, que podem ser encontrados na trilogia e tendem a persistir em seus escritos posteriores.

A primeira característica é uma tentativa deliberada de ultrapassar barreiras disciplinares. Sob esse aspecto Journeys é uma obra emblemática, onde Hirschman manifesta sua disposição de explorar os aspectos políticos do desenvolvimento. Ele combina habilmente uma perspectiva econômica com a pesquisa histórica e institucional.

Esta não foi a primeira vez que Hirschman cruzou a fronteira entre a economia e a ciência política, ${ }^{19}$ e ele continuaria a fazê-lo durante sua carreira. Ele não reduz a economia à política ou vice-versa; em vez disso, assume a tarefa de reintegrar economia e ciência política, dois campos que a economia mainstream havia progressivamente isolado (Frobert; Ferraton, 2003). ${ }^{20}$ Em trabalhos

(18) Isso antecipa o conceito de dissonância cognitiva, que se tornaria popular entre os economistas.

(19) Ver seu National power ant the structure of foreign trade, publicado em 1945, e o capítulo introdutório de Bias for hope (1971). (20) Segundo os autores, Hirschman tomou uma posição intermediária entre

a atitude "imperialista" dos economistas e cientistas políticos e a integração de fatores econômicos e políticos em um único esquema teórico. (Frobert; Ferraton 2003, p. 163). 
posteriores como Passions and interests, ${ }^{21}$ ele também promove o reencontro da economia com a moralidade.

Outro exemplo ainda é o vínculo que pode ser estabelecido entre Development projects e Exit, voice and loyalty, ${ }^{22}$ publicado mais de uma década depois. $\mathrm{O}$ autor realizou a existência de uma forte afinidade entre o conceito de latitude, ao qual o leitor é exposto no primeiro, e o conceito de voz, discutido no último. O conceito de voz enfatiza o papel significativo que a ação política desempenha em muitos processos econômicos. Em países subdesenvolvidos, maus padrões de desempenho tendiam a gerar uma forte preocupação popular e protestos públicos (voz), de tal forma a canalizar os esforços de investimento para atividades que envolviam uma latitude estreita em termos de padrões de desempenho.

Essa tendência de ultrapassar barreiras disciplinares não é uma característica ocasional nos escritos de Hirschman, nem envolve apenas a fronteira entre economia e ciência política. Parece, ao contrário, ser um parti pris consciente, pelo qual o autor também encontra apoio em ferramentas analíticas tomadas de empréstimo de ciências humanas como a ciência política, a sociologia, a psicologia e, de modo mais geral, de disciplinas como filosofia e lingüística. Para Meldolesi (1995, p. 57), The strategy emergiu do trabalho de campo e foi resultado de uma fertilização cruzada de experiências, disciplinas e culturas, no curso de um complexo itinerário entre três continentes distintos.

No trabalho de Hirschman, atravessar as fronteiras entre as disciplinas parece ser análogo a atravessar fronteiras geográficas, culturas e experiências de vida. A familiaridade com todos esses domínios pode explicar a originalidade de sua abordagem de problemas econômicos. Ao ignorar as fronteiras convencionais entre disciplinas ele alargou sua percepção de hipóteses que vão além do campo estrito da economia, assim aguçando sua sensibilidade para conceitos que são parte agora do conhecimento comum dos especialistas, como racionalidade limitada, dissonância cognitiva, custos de transação e falhas de mercado. Em seu esforço de redefinir o escopo da economia política, Hirschman defendeu uma abordagem mais complexa e profunda de seu objeto de estudo, o que é ao mesmo tempo sintoma e causa de sua atitude positiva em relação à pesquisa interdisciplinar.

Em Bias for hope, onde mais uma vez explora as dimensões políticas dos fenômenos econômicos, Hirschman (1971, p. 1) sustenta que essa tendência para ultrapassar barreiras disciplinares surge "quase naturalmente" em qualquer problema que esteja porventura analisando. Embora essa ampla perspectiva não

(21) Existe uma nova edição da tradução brasileira desta obra, lançada pela Editora Record em 2002.

(22) A tradução brasileira foi publicada pela Editora Perspectiva em 1973. 
fosse incomum entre os economistas na época em que escreveu sua trilogia, parece ser mais intensa em seu caso particular. Mais ainda, o caráter coesivo que seus escritos adquiriram em sua carreira pode ser atribuído a essa espécie de displicência (nonchalance) em relação a limites disciplinares, que coexiste com um profundo respeito pelas várias dimensões de seu objeto de estudo. Depois de cruzar a ponte para outras ciências sociais ele continuou a referir-se a conceitos que havia concebido enquanto estava trabalhando em sua trilogia sobre desenvolvimento econômico.

Dois outros aspectos metodológicos são intimamente relacionados a uma atitude de ultrapassar barreiras. Eles consistem em uma estreita conexão entre o trabalho teórico e as recomendações políticas, de um lado, e em uma intensa preocupação com a pesquisa empírica, de outro.

Como já foi dito, Hirschman (1998, p. 80) atribui sua decisão de mudar-se para a América Latina ao desejo de estudar o problema do desenvolvimento em países atrasados. Estava longe de ser uma missão puramente intelectual. Ele queria estudar as causas subjacentes ao subdesenvolvimento e como políticas reformistas de amplo espectro podiam ser implementadas para solucionar seus problemas. Essa mistura de elementos positivos e normativos, que é um traço distintivo em seus escritos, exprime uma atitude geral. Frobert e Ferraton (2003, p. 11) acentuam o fato de que o trabalho de Hirschman é continuamente animado por um engajamento político e existencial resultante de um destino singular. A preocupação com a relevância política levou Hirschman a construir sua teoria econômica em duas frentes simultâneas: uma teórica, que implicava construir uma teoria para explicar o subdesenvolvimento, e uma prática, que envolvia a discussão de um conjunto de recomendações políticas para enfrentá-lo.

O terceiro traço metodológico que vale a pena enfatizar é que, diferentemente de muitos economistas, Hirschman não endossa a idéia de que a função básica de um cientista social é descobrir e analisar regularidades, relações estáveis, seqüências uniformes etc. Díaz-Alejandro (1984) nota que Hirschman estava sempre pronto para aprender com o trabalho empírico, ao condenar simplificações, banalidades e limitações, tanto da ortodoxia quanto da heterodoxia. Ele estava inclinado a abordar problemas com uma mentalidade aberta, que não estava rigidamente limitada por partis pris teóricos.

Nas décadas de 1950 e 1960 havia um déficit de dados estatísticos nos países de Terceiro Mundo estudados por Hirschman. Os manuscritos na Biblioteca Mudd mostram que, embora ele tenha feito um claro esforço para recolher dados secundários sobre o funcionamento da economia, sempre que disponíveis, ele baseou-se principalmente na observação direta. Durante suas viagens à América Latina, à Ásia e à África, realizou centenas de entrevistas com pessoas de 
diferentes formações; visitou projetos do Banco Mundial, em geral longe das cidades grandes, em locais distantes para os quais viajou de trem, pequenos aviões, landrovers e assim por diante. Ele conversou com todo o tipo de pessoa, incluindo autoridades governamentais, técnicos, empresários e professores universitários. Ele levantou e leu a literatura relevante em pelo menos cinco línguas diferentes, tomando notas, transcrevendo passagens significativas e acrescentando seus comentários pessoais.

Hirschman realizou que certas características estruturais das economias em desenvolvimento tornavam a análise ortodoxa inaplicável e distorcida. Ele queria sublinhar a multiplicidade e a desordem criativa da aventura humana, trazer à tona o caráter único de determinada ocorrência, perceber uma maneira inteiramente nova de virar uma esquina da história. Essa meta não podia ser alcançada por uma análise meramente teórica, muito menos pela leitura da literatura disponível sobre desenvolvimento econômico, que era muito pobre na época. Quando Hirschman chegou pela primeira vez à Colômbia, ele estava determinado a entender melhor os padrões de ação dos colombianos, "rather than assume from the outset that they could only be 'developed' by importing a set of techniques they knew nothing about” (Hirschman, 1984, p. 91). É claro, ele veio à América Latina com certas concepções teóricas prévias, mas estava disposto a abandoná-las se a investigação empírica provasse sua incorreção.

\section{Observações finais}

Como pioneiro da economia do desenvolvimento, Albert Hirschman construiu uma estrutura intelectual inovadora, dando uma importante contribuição a esse campo de pesquisa. Seu legado é ainda hoje reconhecido pela comunidade acadêmica de economistas, inclusive aqueles que adotam uma perspectiva diferente, mais convencional, em seu estudo. ${ }^{23}$ Morar na América Latina e viajar para vários países subdesenvolvidos inspirou-o a escrever sua trilogia sobre desenvolvimento econômico. A seu turno, esses escritos fundaram as bases de seus livros e artigos posteriores, que alcançaram um público mais amplo de cientistas sociais.

(23) Não há pleno consenso sobre a importância de sua contribuição, como Taylor (1994, p. 66) afirma ironicamente: "The profession, especially its American branch, does not cope easily with admittedly exploratory, conditional approaches that learn from their own mistakes: historically based lore is not nearly so compelling as theorems, and unbalanced growth looks suspiciously like unbalanced thinking to the mainstream mind". Santiso (2000, p. 96) sustenta que a marginalização de Hirschman do desenvolvimento econômico foi voluntária, e que ele pôde readquirir sua influência graças ao papel proeminente de economistas como Wiliam Coase, Douglas North, Amartya Sen e Daniel Rodrik. 
Nas primeiras seções deste artigo eu fiz uma breve revisão do conteúdo da trilogia de Hirschman sobre desenvolvimento econômico, inspirada por sua estada na América Latina e por suas inúmeras viagens entre 1952 e 1965. A seção 4 foi dedicada à análise de alguns traços metodológicos do trabalho de Hirschman, a saber, a tendência a ultrapassar barreiras disciplinares, uma preocupação profunda com a prática e com a relevância política, e um método de pesquisa empiricamente orientado.

Quero concluir jogando luz sobre dois pontos, que sugerem possibilidades interessantes para uma pesquisa futura sobre o trabalho de Hirschman. A primeira é o que o autor chama de "síndrome do economista visitante", definida como o hábito de fazer recomendações e prescrições peremptórias com base em princípios e remédios econômicos universalmente válidos, a partir de uma convivência mínima com o "paciente" (Hirschman, 1984, p. 93). Missões especialistas que eram enviadas aos países subdesenvolvidos eram freqüentemente acometidas dessa síndrome. Tendiam (e ainda tendem...) a prescrever recomendações políticas sem um exame detido das condições sociais, políticas e econômicas da região. Hirschman usa de ironia para contar ao leitor do que o quartel general do Banco Mundial esperava dele, como consultor estrangeiro, que formulasse rapidamente um plano ambicioso de desenvolvimento econômico, empregando as técnicas de programação avançadas que havia aprendido. Eles argumentavam que a familiaridade com essas técnicas forneciam o apoio necessário para sua missão, "even without close study of local surroundings" (Hirschman, 1984, p. 90).

O fato de Hirschman ser um economista visitante sugere que a "síndrome" tem interessantes conotações psicanalíticas. $\mathrm{O}$ leitor que consulta os documentos na Biblioteca Mudd pode ver que Hirschman foi capaz de evitar essa armadilha. Ele tinha consciência de que os consultores estrangeiros não deveriam apoiar-se em princípios gerais, prescrições abstratas e fórmulas prontas; ao contrário, deveriam engajar-se em uma pesquisa empírica de fôlego de seus "casos", para captar suas peculiaridades e aspectos não usuais. Isso aponta para uma atitude geral inquisitiva, claramente conectada a um método de pesquisa empiricamente orientado.

$\mathrm{O}$ segundo ponto que merece ser mais bem explorado tem a ver com a universalidade dos conceitos e das noções de Hirschman. Sua prolongada experiência de vida na América Latina ensinou-lhe lições que eram de fato aplicáveis a outros países e condições sociais, como ele veio a perceber. Um exemplo disso é o modelo de crescimento desequilibrado que propôs em The strategy: foi originalmente concebido apenas para uma melhor compreensão das mudanças que afetaram países em desenvolvimento, mas mostrou-se útil para enfrentar problemas de economia política dos países avançados. 
No processo de definir sua abordagem do desenvolvimento econômico, Hirschman não abandonou sua pretensão de construir uma teoria universal. Ao contrário, argumentou que dar o devido respeito à diversidade histórica, geográfica e institucional do objeto de pesquisa é essencial para uma teoria que pretende adquirir um escopo universal. Como assinala, uma "mão escondida" benevolente de alguma forma guiou suas explorações teóricas. Ele tinha a intenção de construir uma teoria especialmente voltada para os países subdesenvolvidos e terminou por encontrar uma abordagem que era também válida para o entendimento da mudança e do crescimento em outros países avançados e em desenvolvimento. Em outras palavras, fenômenos aparentemente anômalos observados e analisados nos trópicos foram, mais tarde, "também percebidos nas regiões frias do mundo" (Díaz-Alejandro, 1984, p. 114).

Meldolesi (1995, p. 161) compara o deslocamento de Hirschman de Development projects para Exit, voice and loyalty ao cruzamento das fronteiras entre países atrasados e avançados. A esplêndida carreira intelectual de Hirschman seria depois conscientemente perseguida em ambas as direções. Ao buscar o específico, ele deu a volta toda e encontrou o universal, como afirma na citação abaixo, com a qual encerro este artigo:

It appears, therefore, that the very characteristics on which I had sought to build an economics specially attuned to the underdeveloped countries have a far wider, perhaps even a universal, range and that they define, not a special strategy for the development for a well-defined group of countries, but a much more generally valid approach to the understanding of change and growth. In other words, I set out to learn about others, and in the end learned about ourselves (Hirschman 1984, p. 95 - emphasis added).

\section{Referências bibliográficas}

BOSTAPH, Samuel et al. Remembrance and appreciation roundtable. Dr. Henry William Spiegel (1911-1995). American Journal of Economics and Sociology, v. 57, n. 3, Jul. 1998.

CEPAL - Comissão Econômica para a América Latina e o Caribe. Economic survey of Latin America 1949. 1951.

COSER, Lewis. Refugee scholars in America. Yale University Press, 1984.

DANBY, Colin. Noyola's institutional approach to inflation. Journal of the History of Economic Thought, v. 27, n. 2, p. 161-178, 2005.

DÍAZ-ALEJANDRO, Carlos F. Comment. In: MEIER, G. M.; SEERS D. (Ed.). Pioneers in development. Oxford University Press, 1984.

FROBERT, Ludovic; FERRATON, Cyrille. L'enquête inachevée. Introduction à l'Economie Politique d'Albert O. Hirschman. Paris: Presses Universitaires de France, 2003. 
Ana Maria Bianchi

HIRSCHMAN, Albert O. (1958). The strategy of economic development. Yale University Press, 1965.

(1963). Journeys toward progress. Twentieth Century Fund, 1968.

Development projects observed. Brookings Institution, 1967.

Exit, voice and loyalty: responses to decline in firms, organizations and States. Harvard University Press, 1970.

. A bias for hope. Yale University Press, 1971.

The passions and the interests: political arguments for capitalism before its triumph. Princeton University Press, 1977.

. Essays in trespassing: economics to politics and beyond. Cambridge University Press, 1981.

. A dissenter's confession: 'the strategy of economic development' revisited. In: MEIER, G. M.; SEERS D. (Ed.). Pioneers in development. Oxford University Press, 1984.

. Rival views of market society and other recent essays. Viking/Penguin, 1986.

Press, 1991.

The rhetoric of reaction: perversity, futility, jeopardy. Harvard University

A propensity to self-subversion. Harvard University Press, 1995.

Crossing boundaries. Zone Books, 1998.

MELDOLESI, Luca. Discovering the possible: the surprising world of Albert O. Hirschman. University of Notre Dame Press, 1995a.

SANTISO, Javier. Hirschman's view of development, or the art of trespassing and selfsubversion. CEPAL Review, v. 70, p. 93-109, Apr. 2000.

SARMIENTO, Eduardo. Economic growth and disequilibrium in Colombia. In: TEITEL, S. (Ed.). Towards a new development strategy for Latin America: pathways from Hirschman's thought. Washington, DC: Inter-American Development Bank, 1992.

SONIS, M.; GUILHOTO, J. J. M.; HEWINGS G. J. D. H.; MARTINS, E. B. Linkages, key sectors, and structural change: some new perspectives. The Developing Economies, v. XXXIII, n. 3, p. 233-270, 1995.

SYRQUIN, Moshé. Linkages and the strategy of development. In: TEITEL, S. (Org.). Towards a new development strategy for Latin America - Pathways from Hirschman's thought. Washington, DC: Inter-American Development Bank, 1992.

TAYLOR, Lance. Hirschman's Strategy at thirty-five. In: RODWIN, L.; SCHÖN, D. A. (Ed.). Rethinking the development experience. Essays provoked by the work of Albert O. Hirschman. The Brookings Institution and the Lincoln Institute of Land Policy, 1994. 